\title{
Proposal of initial and maintenance dosing regimens with linezolid for renal impairment patients
}

Hitoshi Kawasuji ${ }^{1}$, Yasuhiro Tsuji ${ }^{2}$, Chika Ogami ${ }^{3}$, Kou Kimoto $^{1}$, Akitoshi Ueno ${ }^{1}$, Yuki Miyajima', Koyomi Kawago', Ippei Sakamaki ${ }^{1}$ and Yoshihiro Yamamoto ${ }^{1 *}$

\begin{abstract}
Background: Linezolid is administered as a fixed dose to all patients despite evidence of overexposure and thrombocytopenia in renal impairment. The aims of this study were to evaluate the risk of thrombocytopenia and the utility of therapeutic drug monitoring (TDM), and to propose alternate dosing regimens in patients with renal impairment.

Methods: We retrospectively reviewed patients $\geq 13$ years old for whom serum linezolid trough concentration $\left(C_{\min }\right)$ was measured during linezolid treatment. Patients with episodes of infection were divided into groups by presence of renal impairment (Rl group) or absence of renal impairment (non-Rl group), and by use of $C_{\min }$-based TDM (TDM group) or not (non-TDM group) during linezolid treatment.

Results: In the 108 patients examined by multivariable analyses, renal impairment was independently associated with increased risk of thrombocytopenia (OR 3.17,95\% Cl 1.10-9.12) and higher $C_{\text {min }}$. Analysis of the utility of TDM in the Rl group showed that clinical failure rate was significantly lower in the TDM subgroup than in the non-TDM subgroup. Furthermore, in the Rl group, dosage adjustments were needed in 90.5\% of the TDM subgroup. All episodes administered a reduced dose of $300 \mathrm{mg}$ every $12 \mathrm{~h}$ in the $\mathrm{Rl}$ group showed $C_{\min } \geq 2.0 \mathrm{mg} / \mathrm{L}$. Additional analysis of 53 episodes in which $C_{\min }$ was measured within $48 \mathrm{~h}$ after starting administration showed that the initial standard dose for 2 days was sufficient to rapidly reach an effective therapeutic concentration in the RI group.

Conclusions: Empirical dose reduction to $300 \mathrm{mg}$ every $12 \mathrm{~h}$ after administration of the initial fixed dose for 2 days and $C_{\text {min }}$-based TDM may improve safety outcomes while maintaining appropriate efficacy among patients with renal impairment.
\end{abstract}

Keywords: Linezolid, Renal impairment, Thrombocytopenia, Therapeutic drug monitoring, Dosing regimen

\footnotetext{
* Correspondence: yamamoto@med.u-toyama.ac.jp

Authorship statement: All authors meet the ICMJE criteria for authorship. 'Department of Clinical Infectious Diseases, Toyama University Graduate School of Medicine and Pharmaceutical Sciences, 2630 Sugitani, Toyama 930-0194, Japan

Full list of author information is available at the end of the article
}

(C) The Author(s). 2021 Open Access This article is licensed under a Creative Commons Attribution 4.0 International License, which permits use, sharing, adaptation, distribution and reproduction in any medium or format, as long as you give appropriate credit to the original author(s) and the source, provide a link to the Creative Commons licence, and indicate if changes were made. The images or other third party material in this article are included in the article's Creative Commons licence, unless indicated otherwise in a credit line to the material. If material is not included in the article's Creative Commons licence and your intended use is not permitted by statutory regulation or exceeds the permitted use, you will need to obtain permission directly from the copyright holder. To view a copy of this licence, visit http://creativecommons.org/licenses/by/4.0/. The Creative Commons Public Domain Dedication waiver (http://creativecommons.org/publicdomain/zero/1.0/) applies to the data made available in this article, unless otherwise stated in a credit line to the data. 


\section{Background}

Linezolid is the first synthetic oxazolidinone agent that is used in the treatment of multi-drug resistant pathogens, such as methicillin-resistant Staphylococcus aureus (MRSA), methicillin-resistant coagulase-negative staphylococci (MR-CoNS), vancomycin-resistant Enterococci, and Mycobacterium tuberculosis [1, 2]. Thrombocytopenia is exposure-dependent adverse effects of linezolid treatment and sometimes leads to discontinuation, even in the short periods [3]. An exposure-response relationship has been clarified for thrombocytopenia and previous studies showed that linezolid trough concentration $\left(C_{\min }\right)$ values above $7-8 \mathrm{mg} / \mathrm{L}$ have consistently been associated with an increased risk of thrombocytopenia [4-9].

Approximately $30-40 \%$ of the administered linezolid is excreted unchanged via the urine, and kidney function is thus a significant source of interpatient variability in linezolid clearance (CL) $[10,11]$. A recent study showed that patients with impaired renal function receiving standard linezolid doses more frequently experienced thrombocytopenia [9]. Renal impairment has been identified as a significant risk factor for increased linezolid $C_{\min }$ in real-world clinical studies $[12,13]$. However, linezolid is currently administered as a fixed dose of $600 \mathrm{mg}$ every $12 \mathrm{~h}$ to all patients despite evidence of overexposure and thrombocytopenia in renal impairment [14]. Accordingly, therapeutic drug monitoring (TDM) and dose modification have been proposed by some authors to improve the safe and effective use of linezolid, especially in the population with renal impairment $[4,6,9,15]$.

Although linezolid overexposure has been reported to be related to several factors including renal impairment $[9,13,15]$, drug-drug interactions [16], and illness severity [17], previous studies have suggested that a reduced dose of $300 \mathrm{mg}$ every $12 \mathrm{~h}$ is better suited to patients with creatinine clearance $\left(\mathrm{CL}_{\mathrm{CR}}\right)<30 \mathrm{~mL} / \mathrm{min}$ or estimated glomerular filtration rate $(\mathrm{eGFR})<60 \mathrm{~mL} / \mathrm{min} /$ $1.73 \mathrm{~m}^{2}$, based on Monte Carlo simulations for sufficient efficacy and safety [9, 18]. However, real-world data from clinical practice to support this recommendation have remained lacking.

The aims of the present study were threefold: 1) to evaluate the relationships between renal impairment, thrombocytopenia and linezolid overexposure; 2) to evaluate whether TDM and TDM-guided dose modification could help prevent and/or recover from linezolid-induced myelosuppression, and prevent treatment failure with good outcome; and 3) to propose alternate initial and maintenance dosing regimens for patients with impaired renal function using actual measurement data from clinical practice.

\section{Methods}

\section{Study design}

We conducted a monocentric, retrospective, observational study from April 2013 to December 2019 among patients $\geq 13$ years old who were treated with linezolid film-coated tablets and/or injections (Zyvox ${ }^{\oplus}$; Pfizer, Tokyo, Japan) because of suspected or documented Gram-positive bacterial infections at Toyama University Hospital. Patients with at least one linezolid serum $C_{\text {min }}$ measured under steady-state conditions, at least $72 \mathrm{~h}$ after linezolid initiation or dose modification, during linezolid treatment were eligible for inclusion. Patients receiving renal replacement therapies including hemodialysis and continuous renal replacement therapy, and patients who were administered linezolid for tuberculosis or nontuberculous mycobacterial infections were excluded. Recurrent infection within the same patient was considered a distinct episode only if it occurred more than 1 week after the initial episode and once antimicrobial therapy had been completed. $\mathrm{CL}_{\mathrm{CR}}$ was estimated using the Cockcroft-Gault formula $\left(\mathrm{CL}_{\mathrm{CRC}-\mathrm{G}}\right)$ and renal impairment was defined as a $\mathrm{CL}_{\mathrm{CRC}-\mathrm{G}} \leq 60 \mathrm{~mL} / \mathrm{min}$ at baseline. Combination antimicrobial therapy was applied whenever clinically needed.

In the present study, linezolid was designed to be started with a fixed dose to all patients, but the initial dose was finally determined at the discretion of the attending physician. Linezolid TDM was performed via infectious disease (ID) consultation upon the request of attending physicians and the results were properly reported to the physicians responsible for the patient. $C_{\min }$ was measured using peripheral venous blood samples collected as clinical practice, just before the next administration after starting linezolid therapy. The times of the intravenous infusions or oral administrations and blood collections were carefully checked, and samples deemed inappropriate were excluded from the analysis. All serum samples obtained were stored at $-80^{\circ} \mathrm{C}$ until linezolid trough measurement. $C_{\text {min }}$ values were suitably measured, especially when ID physicians and/or attending physicians decided it necessary by reference to the course of platelet counts or $C_{\min }$ values, until the end of treatment. When linezolid $C_{\min }>10 \mathrm{mg} / \mathrm{L}$ and thrombocytopenia occurred in the patient, linezolid dose adjustment was recommended by ID physicians, focused on controlling linezolid $C_{\min }$ within the optimal range of $2-8 \mathrm{mg} / \mathrm{L}[4,6,12]$. TDM-based dose adjustments were performed finally at the discretion of the attending physician. Drug dosages were scaled linearly, with a minimum dose modification of $300 \mathrm{mg}$ for the oralroute tablet.

\section{Method of quantification}

Steady-state serum $C_{\min }$ was defined as the total concentration just before administration of linezolid at $\geq 72 \mathrm{~h}$ after linezolid initiation or dose modification. Serum concentrations of linezolid were analyzed by means of a validated HPLC analysis method, as previously described [15]. The intra- and inter-day coefficients of variation 
were always $<5 \%$ and the lower limit of detection was $0.1 \mathrm{mg} / \mathrm{L}$. If multiple steady-state $C_{\min }$ values at the same dosage were measured in one episode, the mean value of all measurements from that episode was used for statistical analyses.

\section{Analysis strategy}

In the present study, episodes were divided into two subgroups, on the basis of the presence of renal impairment (renal impairment group; RI group) or absence of renal impairment (non-RI group). Patients were also divided into those for whom $C_{\min }$-based TDM was used for dosage adjustment during linezolid treatment (TDM group) or in whom linezolid $C_{\min }$ values were measured and assessed only after the end of linezolid treatment, not during treatment (non-TDM group). Among most episodes in non-TDM group, linezolid $C_{\min }$ values could not be measured during linezolid treatment due to delay of the requests for ID consultation from attending physician and/or difficult to secure sufficient time for immediate measurements under the condition of limited human resources capable of measure linezolid concentrations.

\section{Data collection}

For each episode, the following data were retrieved from medical charts and written ID consultations: demographics, type of infection, isolated microorganisms, treatment duration, concomitant medications, linezolid dosage and serum $C_{\min }$ at each instance of TDM, number of all instances of TDM, number of instances of TDM under steady-state conditions, whether TDM for dosage adjustment was performed during linezolid treatment and whether TDM-guided dosage adjustments were performed. Hematological and serum chemistry analyses performed on each day during treatment were retrieved and compared over time.

\section{Clinical outcome}

Episodes were defined as recovered if no clinical, biological and/or radiological evidence of infection was apparent at the end of treatment [4]. Failure was defined as any discontinuation of linezolid therapy before the end of treatment, either because of toxicity or because of persistence of infection [4]. Thirty-day reinfection was defined as infection caused by the same strain at the same infection site within 30 days after end of antimicrobial treatment.

\section{Safety and tolerability outcome}

Thrombocytopenia was defined as platelet count $<112.5 \times$ $10^{3} / \mu \mathrm{L}$ (75\% lower limit of normal) at any time during treatment for episodes with platelet count at or above the lower limit of normal $\left(\geq 150 \times 10^{3} / \mu \mathrm{L}\right)$ at baseline before administration, and $25 \%$ reduction from the baseline value for episodes with low platelet counts at baseline $\left(75-149 \times 10^{3}\right.$ / $\mu \mathrm{L})[9,19]$. Severe thrombocytopenia was defined as platelet count $<75 \times 10^{3} / \mu \mathrm{L}$ for episodes with a normal baseline and platelet count $<50 \times 10^{3} / \mu \mathrm{L}$ for those with low baseline platelets, respectively $[9,19]$.

Recovery from thrombocytopenia was defined as the return and maintenance of platelet count to $>112.5 \times$ $10^{3} / \mu \mathrm{L}$ during therapy for episodes with platelet count at or above the lower limit of normal $\left(\geq 150 \times 10^{3} / \mu \mathrm{L}\right)$ at baseline, or values $>75 \%$ of baseline values with low platelet count at baseline $\left(75-149 \times 10^{3} / \mu \mathrm{L}\right)$, after experiencing thrombocytopenia [4]. Time to the development of thrombocytopenia was also recorded.

\section{Statistical analysis}

The Kolmogorov-Smirnov test was used to assess the normality of data. Descriptive data are expressed as mean \pm standard deviation or median with IQR, and continuous variables were compared using the Mann-Whitney test. Categorical variables were compared using the $\chi^{2}$ test with Yates's correction or Fisher's exact test as necessary. In all analyses, we preliminarily confirmed the affect of multicollinearity of the covariates used in the statistical analysis. Univariate logistic regression analysis was used to investigate variables potentially associated with the occurrence of thrombocytopenia. Multivariate logistic regression analyses were performed with all the independent variables showing $P \leq 0.10$ on univariate analysis as well as with the main variable of renal impairment and variables deemed either clinically relevant or supported in the medical literature. Similarly, uni- and multivariate linear regression analyses were used to identify independent predictors of higher $C_{\min }$ at the fixed dose. A value of $P \leq 0.05$ was considered statistically significant. All statistical analysis and plotting were performed using JMP Pro version 14.2.0 software (SAS Institute, Cary, NC).

\section{Results}

\section{Toxicity and linezolid exposure}

Figure 1 depicts the study flow chart. A total of 118 episodes in 108 patients were included, comprising 35 episodes in 33 patients with renal impairment (RI group) and 83 episodes in 75 patients without renal impairment (non-RI group). All episodes except for six were initially administered as a fixed dose. The remaining 6 episodes were initially reduced to $600 \mathrm{mg}$ per day because of lower body weight $(\leq 45 \mathrm{~kg}$ ) or elderly ( $\geq 88$ years old) which were determined at the discretion of the attending physician. Demographics and clinical baseline characteristics stratified by $\mathrm{CL}_{\mathrm{CR}}$ calculated using the CockcroftGault formula $\left(\mathrm{CL}_{\mathrm{CRC}-\mathrm{G}}\right)$ are summarized in Table 1. Episodes mainly occurred in males (64.4\%) with a median (range) age of 71 years (17-95 years) and a median weight of $57.1 \mathrm{~kg}(30.4-113.0 \mathrm{~kg})$. The main indications 


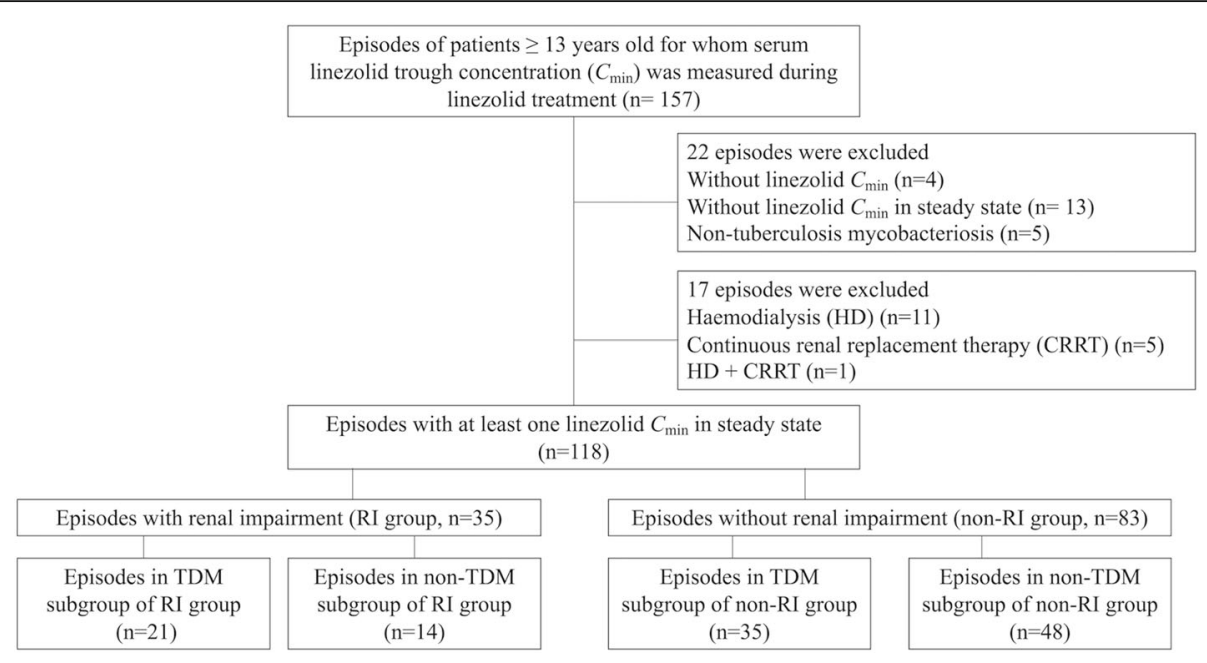

Fig. 1 Study flow. Abbreviations: $C_{\min }$ trough concentration; HD, hemodialysis; CRRT, continuous renal replacement therapy; TDM, therapeutic drug monitoring; Rl, renal impairment

for linezolid therapy were skin and soft tissue infections and surgical site infections followed by bacteremia, bone and joint infections, and respiratory tract infections. Skin and soft tissue infections and surgical site infections were more common in the non-RI group, and bacteremia was significantly more common in the RI group. MRSA and MR-CoNS were the most frequent bacterial isolates. Therapy was empirical in $14.4 \%$ of episodes and combination antimicrobial therapy was prescribed in $54.2 \%$ of episodes.

In the present analyses, a total of 118 episodes contributed 770 linezolid serum $C_{\min }$ concentrations. Median (IQR) number of instances of TDM were 6 (4-11) in the RI group and $6(2-8)$ in the non-RI group. Mean $C_{\min }$ at steady state for the fixed dose of $600 \mathrm{mg}$ every $12 \mathrm{~h}$ in the RI group $(25.6 \pm 10.4 \mathrm{mg} / \mathrm{L})$ was approximately double that in the non-RI group $(14.1 \pm 8.8 \mathrm{mg} / \mathrm{L}, P<0.0001)$ (Table 1). Patients with episodes in the RI group were older and had lower height, body weight, body mass index, and baseline hemoglobin level. Median duration of linezolid therapy was 16 days in the RI group and 21 days in the non-RI group. Among concomitant medications, amlodipine was the most frequent co-prescribed agent both in total and in the RI group.

The rates of occurrence of thrombocytopenia in the two groups are also reported in Table 1. In total, 48 (40.7\%) episodes developed thrombocytopenia and 22 (18.6\%) developed severe thrombocytopenia. Thrombocytopenia occurred more frequently among episodes in the RI group (62.9\%) than in the non-RI group (31.3\%, $P=0.0002)$. Median time from initiation of therapy to development of thrombocytopenia was 12.5 days in both the RI and non-RI groups. In addition, renal impairment was independently associated with an increased risk of thrombocytopenia in uni- and multivariate conditional logistic regression analyses (OR 2.90, 95\%CI 1.13-7.44) (Tables 2 and 3). Platelet count at baseline was also found to be independently associated with thrombocytopenia.

Because many other confounding factors could affect linezolid overexposure, effects were further analyzed by multivariate linear regression using $C_{\min }$ collected after the fixed dose of $600 \mathrm{mg}$ every $12 \mathrm{~h}$ (Table 4). Renal impairment and total body weight were independent predictors of higher $C_{\min }$ at the standard dose $\left(\mathrm{R}^{2}=0.30\right)$. However, linezolid $C_{\min }$ correlated linearly but weakly with $\mathrm{CL}_{\mathrm{CRC}-\mathrm{G}}$ (adjusted $\mathrm{R}^{2}=0.234, P<0.0001$ ) (Supplemental Fig. 1) and total body weight $(0.142, P<0.0001)$. Similarly, linezolid $C_{\min }$ correlated only weakly with other factors including age (adjusted $R^{2}=0.185, P<$ $0.0001)$ and body mass index $(0.047, P=0.013)$. Interepisode coefficients of variation for linezolid $C_{\min }$ were $40.6 \%$ in the RI group and $61.7 \%$ in the non-RI group. Therefore, it should not be overlooked that renal function seems to partially explain the wide interindividual variability in $C_{\min }$ observed in this study population.

\section{Usefulness of TDM}

In the analysis of the usefulness of TDM, the TDM group comprised 56 episodes from 52 patients and the non-TDM group comprised 62 episodes from 61 patients. Episodes in the two groups were further separated by the presence or absence of renal impairment. The distributions of $C_{\min }$ at the standard dose for both groups in the TDM and non-TDM groups were represented in Fig. 2. When assessing these episodes in terms of length of treatment and clinical outcome (Table 5), the duration of linezolid treatment was significantly longer in the TDM group than in the non-TDM group. No significant differences were seen among the TDM and 
Table 1 Characteristics of episodes with or without renal impairment (RI group or non-RI group, respectively)

\begin{tabular}{|c|c|c|c|c|}
\hline & $\begin{array}{l}\text { All, } 118 \text { episodes } \\
\text { in } 108 \text { patients }\end{array}$ & $\begin{array}{l}\text { RI group, } 35 \text { episodes } \\
(29.7 \%) \text { in } 33 \text { patients }\end{array}$ & $\begin{array}{l}\text { Non-RI group, } 83 \text { episodes } \\
(70.3 \%) \text { in } 75 \text { patients }\end{array}$ & $P$-value \\
\hline \multicolumn{5}{|l|}{ Demographics } \\
\hline Age (years), median (IQR) & $71(58.5-78)$ & $78(72-82)$ & $67(47-74)$ & $<0.0001$ \\
\hline Sex (male/female), (\%/\%) & $76 / 42(64.4 / 35.6)$ & $22 / 13(62.9 / 37.1)$ & $54 / 29(65.1 / 34.9)$ & 0.84 \\
\hline Height (m), median (IQR) & $1.61(1.53-1.67)$ & $1.56(1.45-1.63)$ & $1.64(1.56-1.70)$ & 0.0091 \\
\hline Body weight (kg), median (IQR) & $57.1(48.0-64.2)$ & $49.4(45.0-60.3)$ & $59.3(52.2-65.4)$ & 0.0018 \\
\hline Body mass index $\left(\mathrm{kg} / \mathrm{m}^{2}\right)$, median $(\mathrm{IQR})$ & $22.2(20.1-23.7)$ & $21.0(18.9-22.9)$ & $22.4(20.6-24.6)$ & 0.017 \\
\hline \multicolumn{5}{|l|}{ Laboratory, median (IQR) } \\
\hline Serum creatinine $(\mathrm{mg} / \mathrm{dL})$ & $0.65(0.50-1.00)$ & $1.20(0.79-1.49)$ & $0.57(0.48-0.74)$ & $<0.0001$ \\
\hline $\mathrm{CL}_{\mathrm{CRC}-\mathrm{G}}$ & $76.0(49.2-105.4)$ & $36.2(26.9-49.4)$ & $93.7(72.0-118.7)$ & $<0.0001$ \\
\hline Total bilirubin (mg/dL) & $0.4(0.3-0.7)$ & $0.4(0.3-0.8)$ & $0.4(0.3-0.6)$ & 0.85 \\
\hline \multicolumn{5}{|l|}{ Baseline hematological parameters } \\
\hline Hemoglobin concentration (g/dL) & $9.8(8.5-11.6)$ & $8.9(8.3-10.2)$ & $10.1(8.7-11.9)$ & 0.0081 \\
\hline Platelet count $\left(\times 10^{3} / \mu \mathrm{L}\right)$, median (IQR) & $243(177-319)$ & $208(151-284)$ & $255(181-247)$ & 0.062 \\
\hline Low platelet count at baseline $<150 \times 10^{3} / \mu \mathrm{L}, \mathrm{n}(\%)$ & $23(19.5)$ & $8(22.9)$ & $15(18.1)$ & 0.61 \\
\hline Episodes with platelet transfusion during therapy, n (\%) & $8(6.8)$ & $4(11.4)$ & $4(4.8)$ & 0.23 \\
\hline Episodes with DIC, n (\%) & $15(12.7)$ & $5(14.3)$ & $10(12.1)$ & 0.77 \\
\hline \multicolumn{5}{|l|}{ Main reason for linezolid } \\
\hline \multicolumn{5}{|l|}{ Type of infection, n (\%) } \\
\hline $\begin{array}{l}\text { Skin and soft tissue infections, and } \\
\text { surgical site infections }\end{array}$ & 47 (39.8) & $9(25.7)$ & $38(45.8)$ & 0.063 \\
\hline Bacteremia & $36(30.5)$ & $18(51.4)$ & $18(21.7)$ & 0.0021 \\
\hline Bone and joint infections & $31(26.3)$ & $12(34.3)$ & $19(22.9)$ & 0.25 \\
\hline Respiratory tract infections & $26(22.0)$ & $8(22.86)$ & $18(21.69)$ & 1.00 \\
\hline Intra-abdominal infections & $8(6.8)$ & $4(11.4)$ & $4(4.8)$ & 0.23 \\
\hline Mediastinitis & $7(5.9)$ & $2(5.7)$ & $5(6.0)$ & 1.00 \\
\hline Central nerve system infections & $5(4.2)$ & $1(2.9)$ & $4(4.8)$ & 1.00 \\
\hline Endocarditis & $4(3.4)$ & $2(5.7)$ & $2(2.4)$ & 0.58 \\
\hline Urinary tract infections & $4(3.4)$ & $3(8.6)$ & $1(1.2)$ & 0.078 \\
\hline Unknown & $6(5.1)$ & $1(2.9)$ & $5(6.0)$ & 0.67 \\
\hline \multicolumn{5}{|l|}{ Microbiological isolate, $\mathbf{n}(\%)$} \\
\hline MRSA & $63(53.4)$ & $18(51.4)$ & $45(54.2)$ & 0.84 \\
\hline MR-CONS & $25(21.2)$ & $8(22.9)$ & $17(20.5)$ & 0.81 \\
\hline Enterococci & $7(5.9)$ & $3(8.6)$ & $4(4.8)$ & 0.42 \\
\hline Enterococcus faecalis & $2(1.7)$ & $1(2.9)$ & $1(1.2)$ & 0.51 \\
\hline Enterococcus faecium & $5(4.2)$ & $2(5.7)$ & $3(3.6)$ & 0.63 \\
\hline Corynebacterium species & $6(5.1)$ & $4(11.4)$ & $2(2.4)$ & 0.063 \\
\hline Bacillus cereus & $3(2.5)$ & $2(5.7)$ & $1(1.2)$ & 0.21 \\
\hline Other & $8(6.8)$ & $4(11.4)$ & $4(4.8)$ & 0.23 \\
\hline No isolate, Unknown & $11(9.3)$ & $2(5.7)$ & $9(10.8)$ & 0.50 \\
\hline \multicolumn{5}{|l|}{ Linezolid dosage and exposure } \\
\hline Empirical/target therapy, n/n (\%/\%) & 17/101 (14.4/85.6) & 2/33 (5.7/94.3) & 15/68 (18.1/81.9) & 0.093 \\
\hline Dose (mg/kg/day), median (IQR) & $20.7(17.8-24.2)$ & $23.6(18.5-26.7)$ & $20.0(17.3-22.3)$ & 0.017 \\
\hline Mean $C_{\min }$ of fixed doses at steady state & $17.3 \pm 10.5$ & $25.6 \pm 10.4$ & $14.1 \pm 8.8$ & $<0.0001$ \\
\hline
\end{tabular}


Table 1 Characteristics of episodes with or without renal impairment (RI group or non-RI group, respectively) (Continued)

\begin{tabular}{|c|c|c|c|c|}
\hline & $\begin{array}{l}\text { All, } 118 \text { episodes } \\
\text { in } 108 \text { patients }\end{array}$ & $\begin{array}{l}\text { RI group, } 35 \text { episodes } \\
(29.7 \%) \text { in } 33 \text { patients }\end{array}$ & $\begin{array}{l}\text { Non-RI group, } 83 \text { episodes } \\
(70.3 \%) \text { in } 75 \text { patients }\end{array}$ & $P$-value \\
\hline Number of all TDM instances, median (IQR) & $6(3-8)$ & $6(4-11)$ & $6(2-8)$ & 0.33 \\
\hline $\begin{array}{l}\text { Number of TDM instances under steady-state } \\
\text { conditions, median (IQR) }\end{array}$ & $3(2-6)$ & $3(2-6)$ & $3(2-6)$ & 0.47 \\
\hline $\begin{array}{l}\text { Episodes with TDM assessment performed } \\
\text { during linezolid treatment, until end of treatment }\end{array}$ & $56(47.5)$ & $21(60.0)$ & $35(42.2)$ & 0.11 \\
\hline $\begin{array}{l}\text { Episodes needing dosage adjustments to avoid } \\
\text { overexposure, } \mathrm{n}(\%)\end{array}$ & $42 / 56(73.2)$ & 19/21 (90.5) & $22 / 35(62.9)$ & 0.031 \\
\hline Duration of linezolid treatment (days), median (IQR) & $20(11-37.5)$ & $16(11-40)$ & $21(11-36)$ & 0.96 \\
\hline \multicolumn{5}{|l|}{ Co-treatment, n (\%) } \\
\hline Amlodipine & $16(13.6)$ & $7(20.0)$ & $9(10.8)$ & 0.24 \\
\hline Omeprazole & $15(12.7)$ & $4(11.4)$ & $11(13.3)$ & 1.00 \\
\hline Rifampicin & $11(9.3)$ & $5(14.3)$ & $6(7.2)$ & 0.30 \\
\hline Amiodarone & $2(1.7)$ & $1(2.9)$ & $1(1.2)$ & 0.51 \\
\hline Dexamethasone & $2(1.7)$ & $1(2.9)$ & $1(1.2)$ & 0.51 \\
\hline \multicolumn{5}{|l|}{ Other antimicrobials, $\mathrm{n}(\%)$} \\
\hline Meropenem & $26(22.0)$ & $7(20.0)$ & $19(22.9)$ & 0.81 \\
\hline Doripenem & $10(8.5)$ & $1(2.9)$ & $9(10.8)$ & 0.28 \\
\hline Piperacillin/tazobactam & $15(12.7)$ & $7(20.0)$ & $8(9.6)$ & 0.14 \\
\hline Daptomycin & $2(1.7)$ & $1(2.9)$ & $1(1.2)$ & 0.51 \\
\hline Ciprofloxacin & $5(4.2)$ & $0(0.0)$ & $5(6.0)$ & 0.32 \\
\hline Levofloxacin & $7(5.9)$ & $0(0.0)$ & $7(8.4)$ & 0.10 \\
\hline Micafungin & $7(5.9)$ & $2(5.7)$ & $5(6.0)$ & 1.00 \\
\hline Liposomal amphotericin B & $4(3.4)$ & $2(5.7)$ & $2(2.4)$ & 0.58 \\
\hline Voriconazole & $3(2.5)$ & $0(0.0)$ & $3(3.6)$ & 0.55 \\
\hline \multicolumn{5}{|l|}{ Type of toxicity, n (\%) } \\
\hline Thrombocytopenia & $48(40.7)$ & $22(62.9)$ & $26(31.3)$ & 0.0002 \\
\hline $\begin{array}{l}\text { Median time from initiation of therapy to } \\
\text { development of thrombocytopenia }(n=48) \text {, } \\
\text { median days (IQR) }\end{array}$ & $12.5(9.0-15.8)$ & $12.5(10.8-15)$ & $12.5(2.8-17.3)$ & 0.56 \\
\hline Severe thrombocytopenia & $22(18.6)$ & $10(28.6)$ & $12(14.5)$ & 0.12 \\
\hline
\end{tabular}

Abbreviations: $R I$ renal impairment, $C L_{C R C-G}$ creatinine clearance calculated using the Cockcroft-Gault formula, DIC disseminated intravascular coagulopathy, MRSA methicillin-resistant Staphylococcus aureus, MR-CoNS methicillin-resistant coagulase-negative staphylococci, TDM therapeutic drug monitoring

non-TDM groups in failure rate due to persistence of infection. In addition, although thrombocytopenia occurred more frequently among episodes in the TDM group, failure rate due to toxicity and/or persistence of infection tended to be higher in the non-TDM group, but the difference did not reach statistical significance $(P=0.052)$. Failure rates did not differ significantly between the two groups in the non-RI group. On the other hand, although there was no significant difference with respect to the general characteristics, baseline hematological parameters and concomitant drug treatments, failure in general, and due to hematological toxicity were significantly lower in the TDM group of the RI group (Table 5).
In the TDM group, dosage adjustments over time to avoid potential linezolid overexposure were needed in $90.5 \%$ of episodes in the RI group compared to only $62.9 \%$ of episodes in the non-RI group $(P=0.031)$ (Fig. 3 ). TDM-guided dosage reductions allowed recovery from thrombocytopenia and prosecution of therapy until the planned end of treatment with good outcome in 12 (37.5\%) of 32 episodes experiencing thrombocytopenia in the TDM group. Of the episodes needing dose reduction in the TDM group, all those episodes administered a reduced dose of $300 \mathrm{mg}$ every $12 \mathrm{~h}$ in the RI group and in which steady-state $C_{\text {min }}$ of the reduced dose could be measured $(n=13)$ showed $C_{\min } \geq 2.0 \mathrm{mg} / \mathrm{L}$, with no episode experiencing linezolid underexposure (Fig. 4). On 
Table 2 Univariate evaluation of risk factors for development of thrombocytopenia

\begin{tabular}{|c|c|c|c|}
\hline & $\begin{array}{l}\text { Episodes with thrombocytopenia, } \\
n=48(40.7 \%)\end{array}$ & $\begin{array}{l}\text { Episodes without thrombocytopenia, } \\
n=70(59.3 \%)\end{array}$ & $\begin{array}{l}P \text { - } \\
\text { value }\end{array}$ \\
\hline \multicolumn{4}{|l|}{ Demographics } \\
\hline Age (years), median (IQR) & $72(66-77.8)$ & $69(49.5-78)$ & 0.28 \\
\hline Sex (male/female), (\%/\%) & $32 / 16(66.7 / 33.3)$ & $44 / 26(62.9 / 37.1)$ & 0.70 \\
\hline Height (m), median (IQR) & $1.60(1.51-1.67)$ & $1.63(1.54-1.68)$ & 0.18 \\
\hline Body weight (kg), median (IQR) & $51.5(45.4-60.2)$ & $60.0(53.3-65.1)$ & 0.0048 \\
\hline Body mass index $\left(\mathrm{kg} / \mathrm{m}^{2}\right)$, median (IQR) & $21.1(19.1-23.3)$ & $22.5(20.7-25.3)$ & 0.0082 \\
\hline \multicolumn{4}{|l|}{ Laboratory, median (IQR) } \\
\hline Serum creatinine (mg/dL) & $0.80(0.52-1.26)$ & $0.60(0.50-0.83)$ & 0.040 \\
\hline $\mathrm{CL}_{\mathrm{CRC}-\mathrm{G}} \leq 60 \mathrm{~mL} / \mathrm{min}$ & $22(45.8)$ & $13(18.6)$ & 0.0020 \\
\hline Total bilirubin (mg/dL) & $0.4(0.3-0.6)$ & $0.5(0.3-0.73)$ & 0.43 \\
\hline \multicolumn{4}{|l|}{ Baseline haematological parameters, median (IQR) } \\
\hline Hemoglobin concentration (g/dL), median (IQR) & $9.3(8.4-10.5)$ & $10.0(8.7-11.8)$ & 0.033 \\
\hline Platelet count $\left(\times 10^{3} / \mu \mathrm{L}\right)$, median (IQR) & $205(143.5-254.5)$ & $303.5(195-382.5)$ & $\begin{array}{l}< \\
0.0001\end{array}$ \\
\hline $\begin{array}{l}\text { Low platelet count at baseline }<150 \times 10^{3} / \mu \mathrm{L}, \mathrm{n} \\
(\%)\end{array}$ & $13(27.1)$ & $10(14.3)$ & 0.101 \\
\hline $\begin{array}{l}\text { Episodes with platelet transfusion during therapy, } \mathrm{n} \\
(\%)\end{array}$ & $6(12.5)$ & $2(2.9)$ & 0.061 \\
\hline Episodes with DIC, n (\%) & $9(18.8)$ & $6(8.6)$ & 0.16 \\
\hline \multicolumn{4}{|l|}{ Main reason for linezolid } \\
\hline \multicolumn{4}{|l|}{ Type of infection, n (\%) } \\
\hline $\begin{array}{l}\text { Skin and soft tissue infections, and surgical site } \\
\text { infections }\end{array}$ & $17(35.4)$ & $30(42.9)$ & 0.45 \\
\hline Bacteraemia & 19 (39.6) & $17(24.3)$ & 0.103 \\
\hline Bone and joint infections & $13(27.1)$ & $18(25.7)$ & 1.00 \\
\hline Respiratory tract infections & $9(18.8)$ & $17(24.3)$ & 0.51 \\
\hline Intra-abdominal infections & $3(6.3)$ & $5(7.1)$ & 1.00 \\
\hline Mediastinitis & $4(8.3)$ & $3(4.3)$ & 0.44 \\
\hline Central nervous system infections & $0(0.0)$ & $5(7.1)$ & 0.079 \\
\hline Endocarditis & $2(4.2)$ & $2(2.9)$ & 1.00 \\
\hline Urinary tract infections & $2(4.2)$ & $2(2.9)$ & 1.00 \\
\hline Unknown & $3(6.3)$ & $3(4.3)$ & 0.69 \\
\hline \multicolumn{4}{|l|}{ Linezolid dosage and exposure } \\
\hline Empirical/target therapy, n/n (\%/\%) & $6 / 48(12.5 / 87.5)$ & $11 / 59(15.7 / 84.3)$ & 0.79 \\
\hline $\begin{array}{l}\text { Mean } C_{\min } \text { of fixed doses in steady state }(\mathrm{mg} / \mathrm{L}) \\
\text { mean } \pm S D\end{array}$ & $20.6 \pm 10.8$ & $15.3 \pm 9.8$ & 0.0023 \\
\hline $\begin{array}{l}\text { Duration of linezolid treatment (days), median } \\
\text { (IQR) }\end{array}$ & $21(12-42.8)$ & $19.5(10.8-34.3)$ & 0.29 \\
\hline
\end{tabular}

Abbreviations: $C L_{C R C-G}$ creatinine clearance calculated using the Cockcroft-Gault formula, DIC disseminated intravascular coagulopathy

the other hand, in the non-RI group, $62.9 \%$ of episodes in patients were needed for dose reduction, but $23.1 \%$ $(3 / 13)$ of these episodes were under exposure $(<2 \mathrm{mg} / \mathrm{L})$ when administered reduced dose of $300 \mathrm{mg}$ every $12 \mathrm{~h}$ (Fig. 4). Mean $C_{\min }$ at the time of dose reduction to 300 $\mathrm{mg}$ every $12 \mathrm{~h}$ was significantly higher $(10.1 \pm 5.4 \mathrm{mg} / \mathrm{L})$ than that in the non-RI group $(\mathrm{n}=13,5.7 \pm 3.4 \mathrm{mg} / \mathrm{L}$,
$P=0.038)$. Based on these results, a reduced dose of 300 mg every $12 \mathrm{~h}$ may be recommended as a maintenance dose in patients with renal impairment rather than patients with preserved renal function. However, despite using a reduced linezolid dose of $300 \mathrm{mg}$ every $12 \mathrm{~h}$, achieving linezolid $C_{\min }$ within the optimal range was seen in only $46.2 \%(6 / 13)$ of episodes in the RI group 
Table 3 Multivariate conditional logistic regression analysis of variables associated with occurrence of thrombocytopenia

\begin{tabular}{lll}
\hline & OR $(\mathbf{9 5} \% \mathbf{C l})$ & $P$-value \\
\hline Male & $1.25(0.52-3.01)$ & 0.62 \\
Body mass index $\left(\mathrm{kg} / \mathrm{m}^{2}\right)\left(\right.$ per $1-\mathrm{kg} / \mathrm{m}^{2}$ increment) & $0.93(0.72-1.08)$ & 0.25 \\
$\mathrm{CL}_{\mathrm{CRC}-\mathrm{G}} \leq 60 \mathrm{~mL} / \mathrm{min}$ & $2.90(1.13-7.44)$ & 0.027 \\
Hemoglobin concentration $(\mathrm{g} / \mathrm{dL})(\mathrm{per} 1-\mathrm{g} / \mathrm{dL}$ increment) & $0.89(0.72-1.08)$ & 0.23 \\
Platelet count $\left(\times 10^{3} / \mu \mathrm{L}\right)\left(\right.$ per $1.0 \times 10^{3} / \mu \mathrm{L}$ increment) & $0.993(0.989-0.997)$ & 0.0002 \\
Bacteraemia & $1.44(0.51-4.01)$ & 0.49 \\
Duration of linezolid treatment (days) (per 1-day increment) & $1.010(0.989-1.031)$ & 0.36 \\
\hline
\end{tabular}

$\mathrm{R}^{2}=0.189$

Abbreviations: $C L_{C R C-G}$ creatinine clearance calculated using the Cockcroft-Gault formula

and $38.5 \%(5 / 13)$ in the non-RI group (Fig. 4). TDMbased further reduction to $300 \mathrm{mg}$ once daily was needed in $23.8 \%(5 / 21)$ of episodes in the RI group.

\section{Initial and maintenance dosing strategy}

In an additional analysis of 53 episodes in which $C_{\min }$ was measured within $48 \mathrm{~h}$ of starting administration of a fixed $600 \mathrm{mg}$ every $12 \mathrm{~h}$, linezolid $C_{\min }$ of first measurement (first $C_{\min }$ ) at $12,24,36$, and $48 \mathrm{~h}$ after start administration were significantly higher in the RI group than in the non-RI group. The minimal first $C_{\min }$ in the RI group was the $C_{\min }$ of $2.9 \mathrm{mg} / \mathrm{L}$ at $24 \mathrm{~h}$ after start administration and all these episodes in the RI group were above the minimum value of optimal range $(>2 \mathrm{mg} / \mathrm{L})$ even within $48 \mathrm{~h}$ after starting administration (Table 6 and Supplemental Fig. 2). On the other hand, some first $C_{\min }$ of the episodes in the non-RI group were underexposure (Table 6 and Supplemental Fig. 2).
In addition to the observational real-world data from clinical practice, we performed the linezolid dosing simulation of the hypothetical patient with mild renal impairment (60 years old; total body weight, $70 \mathrm{~kg}$; $\mathrm{CL}_{\text {CRC-G }}, 60 \mathrm{~mL} / \mathrm{min}$ ), using recently accepted simulation software "Pycsim" based on population pharmacokinetic and pharmacodynamic model $[15,20]$. When linezolid was initially administered at a dose of $600 \mathrm{mg}$ via hypothetical intravenous drip infusion for $60 \mathrm{~min}$ at 12-h intervals for 2 days, and thereafter reduced dose of $300 \mathrm{mg}$ via hypothetical intravenous drip infusion for 60 min every $12 \mathrm{~h}$, the simulated $C_{\min }$ at the $48 \mathrm{~h}$ after start administration and steady-state $C_{\min }$ at the reduced dose of $300 \mathrm{mg}$ every $12 \mathrm{~h}$ were 9.8 and $5.2 \mathrm{mg} / \mathrm{L}$, respectively. These data suggested that initial administration of a fixed dose for 2 days may be sufficient to rapidly reach an effective therapeutic concentration and empirical dose reduction to $300 \mathrm{mg}$ every $12 \mathrm{~h}$ under TDM control may provide the best balance of safety and efficacy,

Table 4 Uni- and multivariate linear regression analysis of variables associated with linezolid $C_{\min }$ at standard dose of 600 mg every $12 \mathrm{~h}$

\begin{tabular}{|c|c|c|c|c|}
\hline \multirow[t]{2}{*}{ Variables } & \multicolumn{2}{|l|}{ Univariate analysis } & \multicolumn{2}{|l|}{ Multivariate analysis $^{a}$} \\
\hline & Unstandardized $\beta$ coefficient $(95 \% \mathrm{Cl})$ & $P$-value & Unstandardized $\beta$ coefficient $(95 \% \mathrm{Cl})$ & $P$-value \\
\hline Male & $-2.81(-6.95$ to 1.34$)$ & 0.18 & & \\
\hline Age (years) (per 1-year increment) & 0.285 (0.173 to 0.396$)$ & $<0.0001$ & & \\
\hline Height (m) (per 1-m increment) & $-33.71(-51.35$ to -16.07$)$ & 0.0003 & & \\
\hline Body weight (kg) (per 1-kg increment) & $-0.294(-0.427$ to -0.160$)$ & $<0.0001$ & $-0.208(-0.335$ to 0.081$)$ & 0.0016 \\
\hline $\mathrm{CL}_{\mathrm{CRC}-\mathrm{G}} \leq 60 \mathrm{~mL} / \mathrm{min}$ & 11.37 (7.397 to 15.345$)$ & $<0.0001$ & 4.777 (2.793 to 6.760$)$ & $<0.0001$ \\
\hline Total bilirubin > $1.2 \mathrm{mg} / \mathrm{dL}$ & $1.111(-2.960-5.199)$ & 0.59 & & \\
\hline \multicolumn{5}{|l|}{ Co-treatment } \\
\hline Omeprazole & $-1.097(-7.273$ to 5.079$)$ & 0.73 & & \\
\hline Amiodarone & $4.676(-1.243$ to 10.595$)$ & 0.12 & & \\
\hline Amlodipine & $1.037(-13.885$ to 15.960$)$ & 0.89 & & \\
\hline Rifampicin & $2.236(-5.028$ to 9.501$)$ & 0.54 & & \\
\hline Dexamethasone & $0.426(-14.450$ to 15.350$)$ & 0.96 & & \\
\hline
\end{tabular}

${ }^{\mathrm{a}} \mathrm{R}^{2}=0.301$

Abbreviation: $C L_{C R C-G}$ creatinine clearance calculated using the Cockcroft-Gault formula 


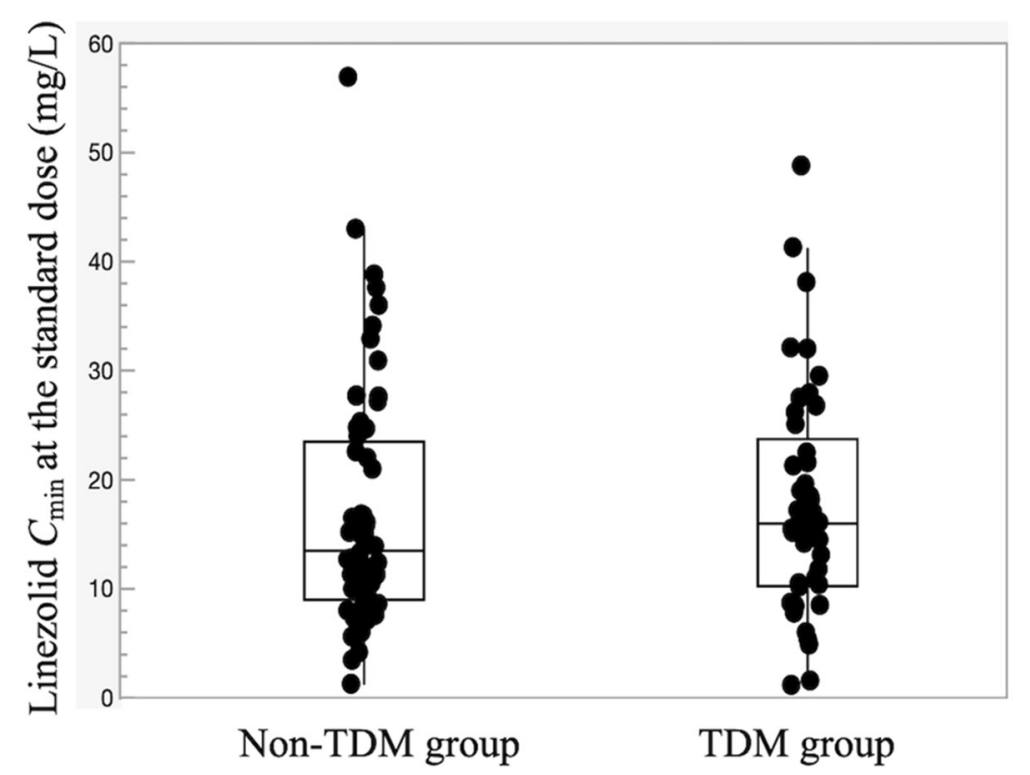

Fig. 2 Boxplots of $C_{\min }$ at the standard dose in the TDM group and non-TDM group. For each boxplot, the horizontal line across the box within each box represents the median, each box represents the range between the 25th and 75th percentiles, the two whiskers represent the minimum and maximum values that are within $1.5 \times I \mathrm{QR}$, and points beyond the whiskers represent outliers. Closed circles represent $C_{\text {min }}$ at the standard dose. Abbreviations: $C_{\min }$, trough concentration; TDM, therapeutic drug monitoring

achieving therapeutic concentrations $(2-8 \mathrm{mg} / \mathrm{L})$ in $\mathrm{pa}-$ tients with $\mathrm{CL}_{\mathrm{CRC}-\mathrm{G}} \leq 60 \mathrm{~mL} / \mathrm{min}$.

\section{Discussion}

Several previous studies have shown that patients with renal impairment more frequently experienced thrombocytopenia during fixed dose treatment $[9,21,22]$. Similarly, in our study, we demonstrate a 3 times greater risk of thrombocytopenia with $\mathrm{CL}_{\mathrm{CRC}-\mathrm{G}} \leq 60 \mathrm{~mL} / \mathrm{min}$. These high frequencies of thrombocytopenia in patients with impaired renal function may be due to increased linezolid concentrations and the absence of specific indications on dose adjustments according to renal function.

Indeed, the present study found that the mean $C_{\min }$ of episodes with renal impairment was approximately double $(25.6 \pm 10.4 \mathrm{mg} / \mathrm{L})$ that of episodes without renal impairment $(14.1 \pm 8.8 \mathrm{mg} / \mathrm{L}, p<0.0001)$. Renal impairment was thus an independent predictor of higher $C_{\min }$ of the fixed dose, consistent with previous reports $[4,12]$.

However, many other covariates, including liver dysfunction, have been reported to affect the pharmacokinetics of linezolid $[6,23,24]$; therefore, a population pharmacokinetics approach would be preferred over the simplistic assessment of trough concentrations to evaluate the influence of renal impairment on linezolid clearance. Although we did not perform population pharmacokinetics analysis, in our previous analysis of linezolid population pharmacokinetics in 81 patients of similar background, about $50 \%$ of elimination was found to be explained by renal clearance [15]. Similarity, several population pharmacokinetics studies using data obtained from clinical practice have also consistently demonstrated renal function to be one of the most important predictor of linezolid clearance $[6,11,18,25]$ and the results of the present study reconfirmed the necessity of effective linezolid dose adjustment for renal impairment patients.

Previous studies have therefore suggested that a reduced dose of $300 \mathrm{mg}$ every $12 \mathrm{~h}$ be recommended for patients with $\mathrm{CL}_{\mathrm{CR}}<30 \mathrm{~mL} / \mathrm{min}$ or eGFR $<60 \mathrm{~mL} / \mathrm{min} /$ $1.73 \mathrm{~m}^{2}$, based on Monte Carlo simulations for sufficient efficacy and safety $[9,18]$. However, to the best of our knowledge, no previous studies have supported this recommendation with actual measurement data from clinical practice. Furthermore, no studies appear to have considered the initial and maintenance dosing regimens separately.

Notably, in the present analyses, we found that an empirical dose reduction to $300 \mathrm{mg}$ every $12 \mathrm{~h}$ under TDM control may provide the best balance of safety and efficacy in Japanese patients with renal impairment, with no patients exposed to sub-therapeutic linezolid concentrations after dose reduction to $300 \mathrm{mg}$ every $12 \mathrm{~h}$ (Table 4). Further, we suggested that the initial fixed dose administration for 2 days was enough to rapidly reach an effective therapeutic concentration in the present additional analyses based on the actual measurement data (Table 6 and Supplemental Fig. 2) and the simulation data of linezolid concentrations using recently accepted simulation software (Supplemental Fig. 3) [15, 20]. 
Table 5 Clinical outcome and length of treatment in TDM and non-TDM groups, further separated by presence or absence of renal impairment (Rl or non-Rl groups)

\begin{tabular}{|c|c|c|c|}
\hline Total & TDM group, $n=56(47.5 \%)$ & Non-TDM group, $n=62$ (52.5\%) & $P$-value \\
\hline Recovery, n (\%) & $38(67.9)$ & $35(56.5)$ & 0.26 \\
\hline Duration of linezolid treatment (days), median (IQR) & $30(19.5-45)$ & $12(9-21.3)$ & $<0.0001$ \\
\hline Failure, n (\%) & $14(25.0)$ & $27(43.6)$ & 0.052 \\
\hline Failure due to persistence of infection, n (\%) & $6(10.7)$ & $2(3.2)$ & 0.15 \\
\hline Failure due to hematological toxicity, n (\%) & $10(17.9)$ & $18(29.0)$ & 0.20 \\
\hline Failure due to other toxicity, n (\%) & $3(5.4)$ & $8(12.9)$ & 0.21 \\
\hline Thirty-day reinfection, n (\%) & $5(8.9)$ & $4(6.5)$ & 0.73 \\
\hline Thrombocytopenia & $32(66.7)$ & $16(33.3)$ & 0.0007 \\
\hline RI group & TDM group, $n=21,(60.0 \%)$ & Non-TDM group, $n=14,(40.0 \%)$ & $P$-value \\
\hline Recovery, n (\%) & $15(71.4)$ & $5(35.7)$ & 0.080 \\
\hline Duration of linezolid treatment (days), median (IQR) & $34(20-46)$ & $11.5(8.8-13.3)$ & $<0.0001$ \\
\hline Failure, n (\%) & $3(14.3)$ & $9(64.3)$ & 0.0038 \\
\hline Failure due to persistence of infection, n (\%) & $1(4.8)$ & $0(0.0)$ & 1.00 \\
\hline Failure due to hematological toxicity, n (\%) & $2(9.5)$ & $8(57.1)$ & 0.0056 \\
\hline Failure due to other toxicity, n (\%) & $0(0.0)$ & $2(14.3)$ & 0.15 \\
\hline Thirty-day reinfection, n (\%) & $3(14.3)$ & $1(7.1)$ & 0.64 \\
\hline Thrombocytopenia & $17(81.0)$ & $5(35.7)$ & 0.012 \\
\hline Non-RI group & TDM group, $n=35$ (42.2\%) & Non-TDM group, $n=48$ (57.8\%) & $P$-value \\
\hline Recovery, n (\%) & $23(65.7)$ & $30(62.5)$ & 0.82 \\
\hline Duration of linezolid treatment (days), median (IQR) & $29(19-45)$ & $13.5(9-22.8)$ & $<0.0001$ \\
\hline Failure, n (\%) & $18(37.5)$ & $11(31.4)$ & 0.64 \\
\hline Failure due to persistence of infection, n (\%) & $2(4.2)$ & $5(14.3)$ & 0.13 \\
\hline Failure due to hematological toxicity, n (\%) & $10(20.8)$ & $8(22.9)$ & 1.00 \\
\hline Failure due to other toxicity, n (\%) & $6(12.5)$ & $3(8.6)$ & 0.73 \\
\hline Thirty-day reinfection, n (\%) & $3(6.3)$ & $2(5.7)$ & 1.00 \\
\hline Thrombocytopenia & $15(42.9)$ & $11(22.9)$ & 0.060 \\
\hline
\end{tabular}

Abbreviations: TDM therapeutic drug monitoring, RI renal impairment

Despite using a reduced linezolid dose of $300 \mathrm{mg}$ every $12 \mathrm{~h}$, Crass et al. demonstrated the simulated probability of achieving linezolid $C_{\min }$ within the therapeutic range of $2-8 \mathrm{mg} / \mathrm{L}$ was only approximately $65 \%$ in simulated patients with eGFR $<60 \mathrm{~mL} /$ $\min / 1.73 \mathrm{~m}^{2}$. Similarly, in the present study, achieving linezolid $C_{\min }$ within the therapeutic range was seen in only $46.2 \%$ of episodes in the RI group even after dose reduction to $300 \mathrm{mg}$ every $12 \mathrm{~h}$ (Fig. 4). Furthermore, TDM-based further reduction to $300 \mathrm{mg}$ once daily was needed in $23.8 \%(5 / 21)$ of episodes in the RI group. On the other hand, in the non-RI group, $63 \%$ of episodes administered the fixed dose were also needed for dose reduction and despite using a reduced linezolid dose of $300 \mathrm{mg}$ every $12 \mathrm{~h}$, achieving linezolid $C_{\min }$ within the therapeutic range was seen in only $38.5 \%(5 / 13)$ in the non-RI group. All these observed results may be due to the large unexplained interindividual variation on clearance.
With regard to linezolid clearance, $\mathrm{CL}_{\mathrm{CR}}$ was identified as the only covariate that significantly explained between subject variation [6], whereas variability due to other unknown factors still remained (the interindividual variability in clearance $=31.3 \%$ ) in our previous study [11] and was nearly equivalent to previously reported values (30.5\% [6] and 35.2\% [18]). Renal dose adjustments alone are thus unlikely to ensure adequate safety and efficacy of linezolid with prolonged therapy.

The use of TDM for patients who require prolonged linezolid treatment is thus essential to any intervention evaluating empirical dose reduction in patients with renal impairment. Also, even in patients with preserved renal function, although empirical dose reduction may not be recommended because of the presence of some episodes with underexposure, TDM and dose reduction under TDM control may also be needed to avoid overexposure and treatment failure. Pea et al. found that TDM-guided dose modification facilitates resolution of 


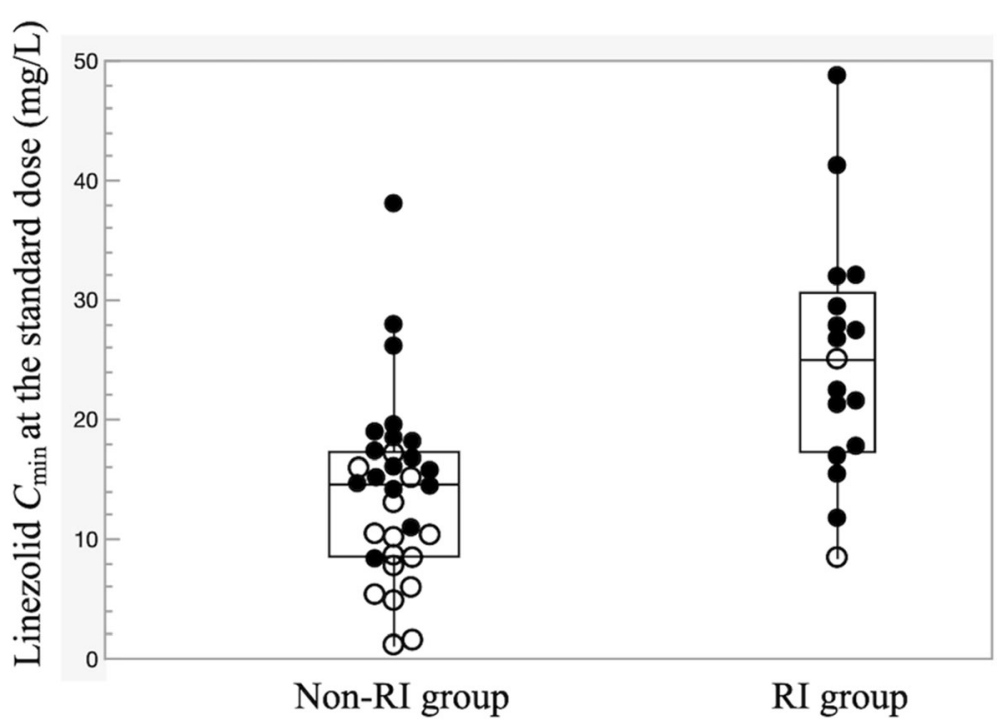

Fig. 3 Boxplots of $C_{\min }$ at the standard dose in the RI and non-Rl groups among the episodes in the TDM group. For each boxplot, the horizontal line across the box within each box represents the median, each box represents the range between the 25th and 75th percentiles, the two whiskers represent the minimum and maximum values that are within $1.5 \times \mathrm{IQR}$, and points beyond the whiskers represent outliers. Closed circles represent $C_{\min }$ values of the episodes in which dose adjustment was performed, and open circles represent $C_{\min }$ values of the episodes in which dose adjustment was not performed. Abbreviations: $C_{\text {min, }}$ trough concentration; Rl, renal impairment, TDM, therapeutic drug monitoring

thrombocytopenia and safe continuation of therapy in one-third of patients who developed toxicity on standard empirical doses [4]. Similarly, we found that TDMguided dosage adjustments to maintain the linezolid $C_{\min }$ range of $2-8 \mathrm{mg} / \mathrm{L}$ allowed recovery from thrombocytopenia and prosecution of therapy until the planned end of treatment, with good outcomes in 12
(37.5\%) of 32 episodes experiencing thrombocytopenia among both patients with renal impairment and preserved renal function.

This study showed limitations inherent to the retrospective design and potential for confounding clinical conditions that cannot be excluded. We used multivariable models to control for confounding patient and

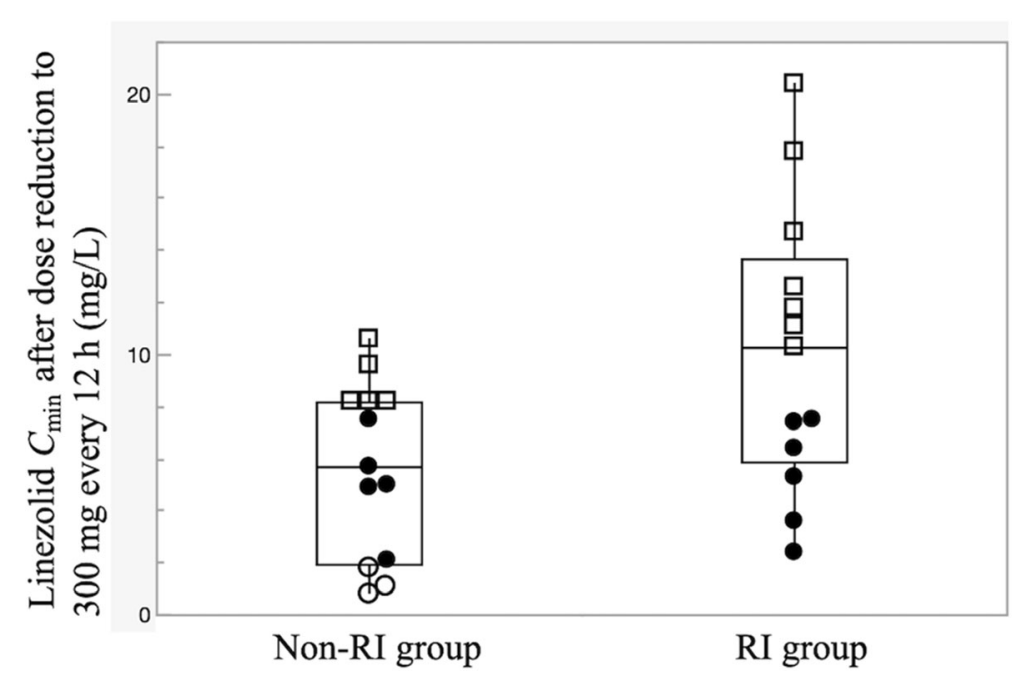

Fig. 4 Boxplots of $C_{\min }$ after dose reduction to $300 \mathrm{mg}$ every $12 \mathrm{~h}$ in the Rl and non-Rl groups. For each boxplot, the horizontal line across the box within each box represents the median, each box represents the range between the 25th and 75th percentiles, the two whiskers represent the minimum and maximum values that are within $1.5 \times \mathrm{IQR}$, and points beyond the whiskers represent outliers. Open circles represent $C_{\text {min }}<$ $2.0 \mathrm{mg} / \mathrm{L}$, closed circles represent $C_{\min }$ within the desired range of $2-8 \mathrm{mg} / \mathrm{L}$, and open square represent $C_{\min }$ values of overexposure $(>8 \mathrm{mg} / \mathrm{L})$. Abbreviations: $C_{\text {min, }}$ trough concentration; Rl, renal impairment 
Table 6 Linezolid $C_{\min }$ of the first measurement (first $C_{\min }$ ) at 12, 24, 36, or $48 \mathrm{~h}$ after starting administration of fixed 600 mg every $12 \mathrm{~h}$ and ratio of first $C_{\min }$ to mean $C_{\min }$ under steady state in the RI group and non-RI group

\begin{tabular}{|c|c|c|c|c|c|c|c|c|c|c|}
\hline \multirow{2}{*}{$\begin{array}{l}\text { Time after } \\
\text { starting } \\
\text { administration } \\
\text { of fixed } 600 \\
\text { mg every } 12 \mathrm{~h} \\
\text { (h) }\end{array}$} & \multicolumn{5}{|c|}{$\begin{array}{l}\text { Linezolid } C_{\min } \text { of first measurement (first } C_{\min } \text { ), mean } \pm \text { SD } \\
\text { (range) }\end{array}$} & \multicolumn{5}{|c|}{$\begin{array}{l}\text { Ratio of first } C_{\min } \text { to mean } C_{\min } \text { under steady state, } \\
\text { median (IQR) }\end{array}$} \\
\hline & $\mathrm{RI}$ group & $\mathrm{n}$ & Non-RI group & $\mathrm{n}$ & $P$-value & $\mathrm{RI}$ group & $\mathrm{n}$ & Non-RI group & $n$ & $P$-value \\
\hline 12 & $8.9 \pm 0.4(8.6-9.4)$ & 3 & $6.2 \pm 3.7(0.2-14.0)$ & 17 & 0.090 & $52.0(24.3-75.6)$ & 3 & $52.0(26.4-80.7)$ & 17 & 0.96 \\
\hline 24 & $12.3 \pm 8.8(2.9-24.3)$ & 7 & $8.3 \pm 3.6(4.8-14.2)$ & 5 & 0.75 & $81.8(64.4-118.3)$ & 7 & $58.2(27.3-64.4)$ & 5 & 0.051 \\
\hline 36 & $18.8 \pm 3.6(16.2-21.3)$ & 2 & $9.6 \pm 7.8(0.5-23.3)$ & 7 & 0.19 & $67.6(41.7-102.0)$ & 2 & $61.3(45.1-77.5)$ & 7 & 0.88 \\
\hline 48 & $25.3 \pm 9.6(15.8-36.1)$ & 4 & $8.7 \pm 4.8(1.4-14.7)$ & 8 & 0.0085 & $62.3(45.8-79.1)$ & 4 & $79.1(55.0-86.8)$ & 8 & 0.44 \\
\hline Total & $15.7 \pm 9.5(2.9-36.1)$ & 16 & $7.7 \pm 4.9(0.2-23.3)$ & 37 & 0.0019 & $58.9(37.8-89.1)$ & 16 & $60.5(38.7-79.9)$ & 37 & 0.71 \\
\hline
\end{tabular}

Abbreviations: $C_{\min }$ trough concentration, first $C_{\min } C_{\min }$ of first measurement, $R /$ renal impairment

clinical factors, but the potential for residual confounding remains. Furthermore, reliance on nominal times of administration and sample collection based on standards of care may have influenced the observed interindividual variability and led to misspecification due to deviations from the sampling protocol in clinical practice. However, our results are consistent with previously published studies, which increases confidence in the results.

\section{Conclusions}

In conclusion, our findings indicate that TDM-guided dose adjustment to maintain the linezolid $C_{\min }$ range of $2-8 \mathrm{mg} / \mathrm{L}$ may be beneficial in preventing treatment failure and in recovering from exposure-dependent thrombocytopenia. Initial fixed-dose administration for 2 days may be enough to rapidly reach an effective therapeutic concentration and empirical dose reduction to $300 \mathrm{mg}$ every $12 \mathrm{~h}$ under TDM control may provide the best balance of safety and efficacy in Japanese patients with $\mathrm{CL}_{\mathrm{CRC}-\mathrm{G}} \leq 60 \mathrm{~mL} / \mathrm{min}$. Further clinical studies involving a large number of patients are necessary to validate our results.

\section{Supplementary Information}

The online version contains supplementary material available at https://doi. org/10.1186/s40360-021-00479-w.

Additional file 1: Supplemental Figure 1. Relationship between linezolid $C_{\min }$ of the fixed dose of $600 \mathrm{mg}$ every $12 \mathrm{~h}$ and creatinine clearance as estimated using the Cockcroft-Gault formula $\left(\mathrm{CL}_{C \mathrm{CRC}-\mathrm{G}}\right)$. Abbreviations: $C_{\text {min }}$, trough concentration; $C_{C R C-G}$, creatinine clearance calculated using the Cockcroft-Gault formula.

Additional file 2: Supplemental Figure 2. Dot plots represent the distribution of linezolid $C_{\text {min }}$ of the first measurement (first $C_{\min }$ ) at 12, 24, 36 , or $48 \mathrm{~h}$ after starting administration of fixed $600 \mathrm{mg}$ every $12 \mathrm{~h}$ in the $\mathrm{Rl}$ group (A) and the non-Rl group (B). Open circles represent $C_{\min }<2.0$ $\mathrm{mg} / \mathrm{L}$, closed circles represent $C_{\min }$ within the desired range of $2-8 \mathrm{mg} / \mathrm{L}$, and open square represent $C_{\min }$ values of overexposure $(>8 \mathrm{mg} / \mathrm{L})$. Abbreviations: $C_{\min }$, trough concentration; fist $C_{\min }, C_{\min }$ of first measurement; Rl, renal impairment.

Additional file 3: Supplemental Figure 3. Simulation of linezolid concentrations using Pycsim software. Shown are screenshots of the application running in the browser-window. This capture is the result of simulation performed after input of the dosing records based on hypothetical patients with mild renal impairment. The dosing records were inputted as initial administration at a dose of $600 \mathrm{mg}$ via hypothetical intravenous drip infusion for $60 \mathrm{~min}$ at 12-h intervals for 2 days, and thereafter reduced dose administration of $300 \mathrm{mg}$ via hypothetical intravenous drip infusion for 60 min every $12 \mathrm{~h}$. The final output is a file consisting of both parts; the left column represents population prediction with pharmacokinetic parameters, the right column represents the simulation curve of total and unbound concentration (black lines: population prediction).

\section{Abbreviations}

MRSA: Methicillin-resistant Staphylococcus aureus; MR-CoNS: Methicillinresistant coagulase-negative staphylococci; $C_{\min }$ : Trough concentration;

$\mathrm{CL}$ : Clearance; TDM: Therapeutic drug monitoring; $\mathrm{CL}_{\mathrm{CR}}$ : Creatinine clearance; eGFR: Estimated glomerular filtration rate; $\mathrm{CL}_{C R C-G}$ : $\mathrm{CL}_{C R}$ calculated using the Cockcroft-Gault formula; ID: Infectious disease; first $C_{\min }$ : $C_{\min }$ of first measurement

\section{Acknowledgements}

The authors sincerely appreciate receiving the 15th incentive Award in the Category of Clinical Research Conferred by the Director of West Japan Branch of the Japanese Society of Chemotherapy. We thank Seiga Nakadachi for supporting the measurements of linezolid concentrations.

\section{Authors' contributions}

HK and YT contributed to the acquisition of data, participated in study design, contributed to the serum concentration measurement, analyzed and interpreted the data, and drafted the manuscript. CO contributed to the conception and design, acquisition of data, and the serum concentration measurement. HK, KK1, AU, YM, KK2, IS, and YY were clinical investigators of the trials and responsible for the medical care of trial participants, communication with the research ethics committee, protocol, informed consent, data integrity and reporting. YY was responsible for the overall organization and coordination of the trial. All authors contributed to the writing of the final manuscript. All members of the present study team contributed to the management or administration of the trial. The author(s) read and approved the final manuscript.

\section{Funding}

This work was supported by Japan Society for the Promotion of Science (JSPS) KAKENHI grant numbers JP19K08950 and JP20K07189. The funding bodies played no role in the design of the study and collection, analysis, and interpretation of data and in writing the manuscript.

\section{Availability of data and materials}

All data generated or analysed during this study are included in this published article. 


\section{Declarations}

\section{Ethics approval and consent to participate}

This study was performed in conformity with the Declaration of Helsinki after approval by the ethics review board of University of Toyama (approval number: clinical 24-118), and all patients provided written informed consent regarding the publication of medical data.

\section{Consent for publication}

Not applicable.

\section{Competing interests}

The authors declare that they have no competing interests.

\section{Author details}

'Department of Clinical Infectious Diseases, Toyama University Graduate School of Medicine and Pharmaceutical Sciences, 2630 Sugitani, Toyama 930-0194, Japan. ${ }^{2}$ Center for Pharmacist Education, School of Pharmacy, Nihon University, 7-7-1 Narashinodai, Chiba 274-8555, Japan. ${ }^{3}$ Department of Medical Pharmaceutics, Faculty of Pharmaceutical Sciences, University of Toyama, 2630 Sugitani, Toyama 930-0194, Japan.

\section{Received: 21 August 2020 Accepted: 21 February 2021}

Published online: 04 March 2021

\section{References}

1. Perry $\mathrm{CM}$, Jarvis B. Linezolid: a review of its use in the management of serious gram-positive infections. Drugs. 2001;55:525-51.

2. Lee M, Lee J, Carroll MW, Choi H, Min S, Song T, Via LE, Goldfeder LC, Kang E, Jin B, Park H, Kwak H, Kim H, Jeon HS, Joh JS, Chen RY, Olivier KN, Shaw PA, Follmann D, Song SD, Lee JK, Lee D, Kim CT, Dartois V, Park SK, Cho SN, Barry CE. Linezolid for treatment of chronic extensively drug-resistant tuberculosis. N Engl J Med. 2012;367(16):1508-18.

3. Vinh DC, Rubinstein E. Linezolid: a review of safety and tolerability. J Inf Secur. 2009:59(Suppl 1):59-74.

4. Pea F, Viale P, Cojutti P, Pin BD, Zamparini E, Furlanut M. Therapeutic drug monitoring may improve safety outcomes of long-term treatment with linezolid in adult patients. J Antimicrob Chemother. 2012;67(8):2034-42.

5. Cattaneo D, Orlando G, Cozzi V, Cordier L, Baldelli S, Merli S, Fucile S, Gulisano C, Rizzardini G, Clementi E. Linezolid plasma concentrations and occurrence of drug-related haematological toxicity in patients with grampositive infections. Int J Antimicrob Agents. 2013;41(6):586-9.

6. Matsumoto K, Shigemi A, Takeshita A, Watanabe E, Yokoyama Y, Ikawa K, Morikawa N, Takeda Y. Analysis of thrombocytopenic effects and population pharmacokinetics of linezolid: a dosage strategy according to the trough concentration target and renal function in adult patients. Int J Antimicrob Agents. 2014;44(3):242-7.

7. Boak LM, Rayner CR, Grayson ML, Paterson DL, Spelman D, Khumra S, Capitano B, Forrest A, Li J, Nation R, Bulitta JB. Clinical population pharmacokinetics and toxicodynamics of linezolid. Antimicrob Agents Chemother. 2014;58(4):2334-43.

8. Dong HY, Xie J, Chen LH, Wang TT, Zhao YR, Dong YL. Therapeutic drug monitoring and receiver operating characteristic curve prediction may reduce the development of linezolid-associated thrombocytopenia in critically ill patients. Eur J Clin Microbiol Infect Dis. 2014;33(6):1029-35.

9. Crass RL, Cojutti PG, Pai MP, Pea F. A reappraisal of linezolid dosing in renal impairment to improve safety. Antimicrob Agents Chemother. 2019;63: e00605-19.

10. Slatter JG, Stalker DJ, Feenstra KL, Welshman IR, Bruss JB, Sams JP, Johnson MG, Sanders PE, Hauer MJ, Fagerness PE, Stryd RP, Shobe EM. Pharmacokinetics, metabolism, and excretion of linezolid following an oral dose of $[(14) C]$ linezolid to healthy human subjects. Drug Metab Dispos. 2001;29(8):1136-45.

11. Tsuji Y, Yukawa E, Hiraki Y, Matsumoto K, Mizoguchi A, Morita K, Kamimura $H$, Karube $Y$, To H. Population pharmacokinetics and pharmacodynamics of linezolid-induced thrombocytopenia in hospitalized patients. J Clin Pharmacol. 2013;53(9):967-73.

12. Morata L, Calle CDL, Gómez-Cerquera JM, Manzanedo L, Casals G, Burnet M, Cobos-Trigueros N, Martínez JA, Mensa J, Soriano A. Risk factors associated with high linezolid trough plasma concentrations. Expert Opin Pharmacother. 2016;17(9):1183-7.
13. Pea F, Cojutti PG, Baraldo M. A 10-year experience of therapeutic drug monitoring (TDM) of linezolid in a hospital-wide population of patients receiving conventional dosing: is there enough evidence for suggesting TDM in the majority of patients? Basic Clin Pharmacol Toxicol. 2017;121(4): 303-8.

14. Brier ME, Stalker DJ, Aronoff GR, Batts DH, Ryan KK, O'Grady M, Hopkins NK, Jungbluth GL. Pharmacokinetics of linezolid in subjects with renal dysfunction. Antimicrob Agents Chemother. 2003;47(9):2775-80.

15. Tsuji Y, Holford NHG, Kasai H, Ogami C, Heo YA, Higashi Y, Mizoguchi A, To $\mathrm{H}$, Yamamoto $\mathrm{Y}$. Population pharmacokinetics and pharmacodynamics of linezolid-induced thrombocytopenia in hospitalized patients. Br J Clin Pharmacol. 2017;83(8):1758-72.

16. Douros A, Grabowski K, Stahlmann R. Drug-drug interactions and safety of linezolid, tedizolid, and other oxazolidinones. Expert Opin Drug Metab Toxicol. 2015:11(12):1849-59.

17. Dong $H$, Xie J, Wang $T$, Chen L, Zeng X, Sun J, Wang X, Dong Y. Pharmacokinetic/pharmacodynamic evaluation of linezolid for the treatment of staphylococcal infections in critically ill patients. Int J Antimicrob Agents. 2016;48(3):259-64.

18. Sasaki T, Takane H, Ogawa K, Isagawa S, Hirota T, Higuchi S, Horii T, Otsubo $\mathrm{K}$, leiri I. Population pharmacokinetic and pharmacodynamic analysis of linezolid and a hematologic side effect, thrombocytopenia, in Japanese patients. Antimicrob Agents Chemother. 2011;55(5):1867-73.

19. Cojutti PG, Merelli M, Bassetti M, Pea F. Proactive therapeutic drug monitoring (TDM) may be helpful in managing long-term treatment with linezolid safely: findings from a monocentric, prospective, open-label, interventional study. J Antimicrob Chemother. 2019;74:3588-95.

20. Ogami C, Tsuji Y, Nishi Y, Kawasuji H, To H, Yamamoto Y. External evaluation of population pharmacokinetics and pharmacodynamics in linezolidinduced thrombocytopenia: the transferability of published models to different hospitalized patients. Ther Drug Monit. 2020. https://doi.org/10.1 097/FTD.0000000000000816 Online ahead of print.

21. Wu VC, Wang YT, Wang CY, Tsai IJ, Wu KD, Hwang JJ, Hsueh PR. High frequency of linezolid-associated thrombocytopenia and anemia among patients with end-stage renal disease. Clin Infect Dis. 2006;42(1):66-72

22. Takahashi Y, Takesue Y, Nakajima K, Ichiki K, Tsuchida T, Tatsumi S, Ishihara M, Ikeuchi H, Uchino M. Risk factors associated with the development of thrombocytopenia in patients who received linezolid therapy. J Infect Chemother. 2011;17(3):382-7.

23. Morata L, Cuesta M, Rojas JF, Rodriguez S, Brunet M, Casals G, Cobos N, Hernandez C, Martínez JA, Mensa J, Soriano A. Risk factors for a low linezolid trough plasma concentration in acute infections. Antimicrob Agents Chemother. 2013;57(4):1913-7.

24. Zhang SH, Zhu ZY, Chen Z, Li Y, Zou Y, Yan M, Xu Y, Wang F, Liu MZ, Zhang M, Zhang BK. Population pharmacokinetics and dosage optimization of linezolid in patients with liver dysfunction. Antimicrob Agents Chemother. 2020;64(6):e00133-20.

25. Meagher AK, Forrest A, Rayner CR, Birmingham MC, Schentag JJ. Population pharmacokinetics of linezolid in patients treated in a compassionate-use program. Antimicrob Agents Chemother. 2003;47:548-53.

\section{Publisher's Note}

Springer Nature remains neutral with regard to jurisdictional claims in published maps and institutional affiliations.

Ready to submit your research? Choose BMC and benefit from:

- fast, convenient online submission

- thorough peer review by experienced researchers in your field

- rapid publication on acceptance

- support for research data, including large and complex data types

- gold Open Access which fosters wider collaboration and increased citations

- maximum visibility for your research: over $100 \mathrm{M}$ website views per year

At $\mathrm{BMC}$, research is always in progress.

Learn more biomedcentral.com/submission 